\title{
Prevalence Characteristics and Prediction of Coal Workers' Pneumoconiosis in the Tiefa Colliery in China
}

\author{
Hongbo LIU ${ }^{1,2}$, Zhifeng TANG1, Dong WENG', Yongli YANG ${ }^{3}$, \\ Lujia TIAN $^{1}$, Zhiwen DUAN ${ }^{1}$ and Jie CHEN ${ }^{1}$ *
}

\author{
${ }^{1}$ Division of Pneumoconiosis, School of Public Health, China Medical University, 92 North 2nd Road, \\ Shenyang 110001, China \\ ${ }^{2}$ Department of Health Statistics, School of Public Health, China Medical University, 92 North 2nd Road, \\ Shenyang 110001, China \\ ${ }^{3}$ Division of Occupational Disease, General Hospital of Tiefa Colliery, Diaobingshan, Liaoning Province \\ 112700, China
}

Received October 20, 2008 and accepted February 9, 2009

\begin{abstract}
To explore characteristics of the development of coal workers' pneumoconiosis (CWP) at present and trend in the future, we investigated 16,154 coal miners exposed to dust for at least $1 \mathrm{yr}$ in the Tiefa Colliery in China. Occupational categories were divided into tunneling, mining, combining and helping. Four cohorts (before 1958, 1958-, 1968-, and after 1978) were created according to years of first exposure. Life-Table Method was used to calculate cumulative incidence rates of CWP adjusted by duration of dust exposure and predict the number of the new CWP patients. Results indicated that cumulative incidence rates of CWP in four cohorts were $26.65 \%, 18.94 \%, 1.15 \%$, and $0.06 \%$, respectively $\left(\chi^{2}=493.57, p<0.0001\right)$. The 55 -yr cumulative rate of CWP of tunneling miners $(25.90 \%)$ or that of combining miners (14.53\%) was statistically higher than that of mining miners $(\mathbf{7 . 2 6 \%})$ or that of helping miners $(\mathbf{0 . 8 9 \%})$. The number of new CWP patients predicted in future was approximately 77. New CWP patients predicted would mainly occur among coal miners with first dust exposure in 1958-1967 and those working at tunneling. Most of them could be diagnosed in the age group from 45 to 75 and in the period of the next $20 \mathrm{yr}$ from 2008 to 2028.
\end{abstract}

Key words: Coal workers' pneumoconiosis, Prevalence, Prediction, Life-table method

\section{Introduction}

Coal workers' pneumoconiosis (CWP) is a lung disease caused by inhaling coal dust or silicon dust or both for an extended period of time. Unfortunately, there is no cure for the damage that those dusts has already done to the lungs ${ }^{1,2)}$. At present, some studies have shown that the number of coal miners with CWP is decreasing ${ }^{3-5}$. But those analyses were mostly based on patient's data, or autopsy datasets ${ }^{6-8)}$. Due to loss of appropriate denominator data, it is difficult to systemically analyze those

*To whom correspondence should be addressed.

Hongbo LIU and Zhifeng TANG contributed equally to this work. data by the different characteristics and to clearly indicate the prevalence of CWP. There were researchers having reported the rates of prevalence of CWP based on the population. Data in those studies were mainly abstracted from existing datasets ${ }^{9,10)}$, or combined data collected from several coal mines ${ }^{11,12)}$. Because of the presence of the heterogeneity of coal miners, data had wide variations on some characteristics ${ }^{13)}$. Therefore, it is inappropriate to assess the effect of prevention and controlling strategies according to the trend of CWP resulting from these studies. For the purpose of effectively preventing and controlling CWP, it is necessary to search for the characteristics of the disease incidence in present and in the past, predict those in the future, and further find 
out the long-term changes of the incidence of the disease as well as the cause of their different changes in relatively steady coal miners.

In present study, we conducted a longitudinal retrospective study with all dust-exposed coal miners at the same colliery in China to explore characteristics of the development and incidence of CWP at present. We further predicted the trend of CWP in the future, to provide scientific evidence for reasonable decisions favorable to control the incidence of CWP.

\section{Subjects and Methods}

\section{Settings}

The study was conducted in the Tiefa Colliery in China. The colliery was started to establish in the early 1950 s and was formally founded in the late 1950s. By 2007, there were 8 mines with similarities in the nature of the coal (Kennel Coal) and mining procedure, especially the proportion of carbon and silica. In 1950s, dust prevention measures were poor. At the start of the 1960 s, wet operation and ventilation devices were used to decrease dust concentration. In the last 1960 s or later, the totally mechanized coal mining equipment was installed in the plants, and dust concentration decreased evidently. There were further improvements on decreasing dust concentration between the late 1970s and the early 1980s by using other advanced machinery, and were evidently effective in reducing dust exposure levels.

\section{Cohort description}

The cohort comprised overall coal miners who had been exposed to dust on their work in Tiefa Colliery. Each member of the cohort was exposed to dust for at least $1 \mathrm{yr}$ and had physical examination cards and detailed records of their occupational history as well as X-ray chest films in the colliery. Those coal miners departing from the dust job and having been deceased were also included if they had worked for $1 \mathrm{yr}$ or above in the mine. In Tiefa Colliery, tunneling miners must be offered a chest $\mathrm{X}$-ray approximately every $1-2 \mathrm{yr}$, mining miners every $2-3 \mathrm{yr}$, and helping miners every $3-5 \mathrm{yr}$. For $0^{+} \mathrm{CWP}$ patients, tunneling miners must be offered a chest X-ray approximately every year, mining miners every $2 \mathrm{yr}$, and helping miners every $3 \mathrm{yr}$. The physical examination of coal miners was conducted by the division of occupational disease, general hospital of Tiefa Colliery. Chest radiograph of CWP patients were read and diagnosed independently by 5 qualified experts who were members of Tieling municipal pneumoconiosis diagnosis committee. The diagnosis was based on the Chinese diagnosis standard for pneumoconiosis and corresponding standard films of pneumoconiosis.

\section{Work histories}

Each subject's work history in the Tiefa Colliery was investigated, which comprised a detailed record of each job, including starting and ending dates, occupational category, and other information. The occupational category was determined by reviewing the job description with the participant ${ }^{14}$. In the study, we divided occupational category into four groups according to their levels and kind of dust exposure: tunneling, mining, combining, and helping. Both tunneling and mining miners were working in the underground areas and faced up directly to the place where dust was produced. The tunneling miners' job included pneumatic drilling, blasting and lashing of the hard rock materials to create tunnels. The mining miner is located at the coalface and their jobs involved in drilling, blasting, cutting, loading of the coal. The helping miners' job mainly includes maintenance, transportation, washing plant and cinders, etc., and helping miners didn't face up directly to the place where dust was produced.

Besides, many miners had experienced several jobs. For these miners, we classified miners as tunneling if they had involved in tunneling for more than half of dustexposed duration. The miners were classified as mining if their duration of tunneling was less than $2 \mathrm{yr}$ and more than half of dust-exposed duration. We classified miners as combining if their duration of tunneling was more than $2 \mathrm{yr}$ but not more than half of dust-exposed duration.

\section{Measure variables}

The database should include demographic details, work history records, and date of retirement. The most recent chest radiograph of each member of the cohort should be provided. In addition, for coal miners who were diagnosed as CWP, date of diagnosis and period of CWP were included. For deceased subjects, date and cause of death should be obtained. Most of data in the study were elicited from personnel records in Manpower Resource Section of the Tiefa Colliery. The records of health status were obtained from the department of industry hygiene and occupational disease of the Tiefa Colliery. For a few subjects with incomplete records, we checked those records by face-to-face or telephone interview with coal miners, or with the family members or workmates of deceased coal miners. The data were collected in December 2007.

\section{Statistical analysis}

Duration of dust exposure was calculated for each coal miner by the accumulation of the periods of all jobs with dust exposure. Duration of each job was calculated by taking the difference between the starting date and the ending date of dust exposure. Observed person-year accumulation started on the first day of dust exposure and 
Table 1. Characteristics of coal miners with and without CWP in this study (mean \pm SD)

\begin{tabular}{|c|c|c|c|}
\hline \multicolumn{2}{|c|}{ Characteristics } & \multirow{2}{*}{$\begin{array}{c}\text { With CWP }(\mathrm{n}=236) \\
153\end{array}$} & \multirow{2}{*}{$\begin{array}{c}\text { Without CWP }(\mathrm{n}=15,918) \\
15,390\end{array}$} \\
\hline \multirow{4}{*}{ Status } & Alive & & \\
\hline & Retired & 14 & 1,497 \\
\hline & Employed & 139 & 13,893 \\
\hline & Deceased & 83 & 528 \\
\hline \multirow{4}{*}{$\begin{array}{l}\text { Occupational } \\
\text { categories }(\%)\end{array}$} & Tunneling & $201(85.17)$ & $5,598(35.17)$ \\
\hline & Mining & $23(9.75)$ & $3,129(19.66)$ \\
\hline & Combining & $9(3.81)$ & $675(4.24)$ \\
\hline & Helping & $3(1.27)$ & $6,516(40.93)$ \\
\hline \multicolumn{2}{|c|}{ Year of birth } & $1936 \pm 7.72$ & $1962 \pm 11.05 * *$ \\
\hline \multicolumn{2}{|c|}{ Year of first exposure } & $1959 \pm 6.30$ & $1984 \pm 10.59 * *$ \\
\hline \multicolumn{2}{|c|}{ Age at first exposure } & $23.41 \pm 5.22$ & $21.93 \pm 4.56$ \\
\hline \multicolumn{2}{|c|}{ Duration of exposure (yr) } & $23.35 \pm 7.08$ & $16.86 \pm 8.05^{* *}$ \\
\hline \multicolumn{2}{|c|}{ Time since first exposure (yr) } & $29.37 \pm 9.98$ & $21.03 \pm 10.59 * *$ \\
\hline
\end{tabular}

Compared with coal miners with CWP: ${ }^{* *} p<0.01$.

ended at the date when this study ended (Dec, 31 2007), or coal miners were diagnosed as CWP, died, or failed to follow-up.

For analysis on the overall trend of time of dust exposure, four cohorts were created: before 1958, 1958-, 1968-, and after 1978. Cumulative incidence rates, adjusted by duration of dust exposure $(<10 \mathrm{yr}, 10 \mathrm{yr}-$ and $\geq 20 \mathrm{yr})$, were calculated and tested in four cohorts and four occupational categories (tunneling, mining, combining and helping) by using Life Table Method and Peto Log-Rank Test in the same observed years. To predict the future prevalence of CWP, we calculated the cumulative incidence rate of CWP in the different cohorts and occupational categories, and then the average person-year incidence rate $(p$, $p=$ cumulative incidence rate/observed years) were obtained. Additionally, we investigated the age distribution of healthy coal miners and life expectancy of inhabitant of this region in 2007. According to these data, we estimated the number of the new possible CWP patients in the future, that is, the number of predicted new possible patients=the life expectancy of healthy coal miners $x$ the number of healthy coal miners $x$ the average person-year incidence rate.

All statistical procedures were accomplished by the SAS program PROC LIFETEST [SAS Institute, Inc.]. Statistical significance was declared if the $p$ value was less than the alpha $(\alpha)$ level of 0.05 .

\section{Results}

\section{Basic characteristics}

This study included 16,154 coal miners, of whom $15,543(96.22 \%)$ were alive (14,032 currently employed coal miners and 1,511 retirees), and 611 (3.78\%) were deceased. 437 coal miners were failed to follow-up, of whom 296 miner and 141 retirees switched the job or moved to other places. By the end of 2007, all subjects had worked for an average of $16.96 \mathrm{yr}$, and on average, $21.15 \mathrm{yr}$ had elapsed since first dust exposure. The subjects with CWP and those without CWP included 236 and 15,918 miners respectively (Table 1). Among CWP patients, 212 miners were diagnosed as I period CWP, 20 were II period, and 4 were III period.

\section{Prevalence of $C W P$}

Among the coal miners with different durations of dust exposure $(<10 \mathrm{yr}, 10-\mathrm{yr}$ and $\geq 20 \mathrm{yr})$, cumulative incidence rates of CWP, in the $55 \mathrm{yr}$ of observation period, were $0.37 \%, 12.15 \%$ and $17.73 \%$, respectively. The distributions of incidence rates were significantly different in three different durations of dust exposure $\left(\chi^{2}=7.419\right.$, $p=0.0245$ ). There was enough evidence to support that the duration of dust exposure was related to the incidence rate of CWP ${ }^{15}$. In our study, the proportions of coal miners with different exposure durations in four cohorts with different years of first exposure were significantly different, and those in four occupational categories also existed significant difference (Table 2). Consequently, in analysis of prevalence of CWP, the duration of dust exposure was considered as a stratified factor in order to clearly describe the incidence rates of CWP.

Figure 1 shows cumulative incidence rates of CWP in four cohorts with different years of first exposure (before 1958, 1958-, 1968-, after 1978) after controlling for duration of dust exposure. They were $30.54 \%, 18.35 \%$, $1.12 \%$, and $0.06 \%$ after $30 \mathrm{yr}$ of observation period, 
Table 2. The proportion of coal miners in different years of first exposure and occupational categories

\begin{tabular}{|c|c|c|c|c|c|c|c|c|}
\hline \multirow{2}{*}{\multicolumn{2}{|c|}{ Duration of dust exposure (yr) }} & \multicolumn{3}{|c|}{ With CWP } & \multicolumn{3}{|c|}{ Without CWP } & \multirow{2}{*}{ Total } \\
\hline & & $<10$ & 10 & $\geq 20$ & $<10$ & 10 & $\geq 20$ & \\
\hline \multirow{4}{*}{$\begin{array}{l}\text { Years of first } \\
\text { exposure }\end{array}$} & Before 1958 & 1 & 14 & 52 & 12 & 19 & 265 & 363 \\
\hline & $1958-$ & 1 & 51 & 96 & 37 & 264 & 683 & 1,132 \\
\hline & $1968-$ & 1 & 12 & 6 & 293 & 471 & 1,533 & 2,316 \\
\hline & $1978-$ & 0 & 1 & 1 & 3,095 & 5,134 & 4,112 & 12,343 \\
\hline \multirow{4}{*}{$\begin{array}{l}\text { Occupational } \\
\text { categories }\end{array}$} & Tunneling & 3 & 72 & 126 & 1,396 & 1,913 & 2,289 & 5,799 \\
\hline & Mining & 0 & 4 & 19 & 618 & 1,164 & 1,347 & 3,152 \\
\hline & Combining & 0 & 2 & 7 & 27 & 211 & 437 & 684 \\
\hline & Helping & 0 & 0 & 3 & 1,396 & 2,600 & 2,520 & 6,519 \\
\hline
\end{tabular}

- Years of first exposure: With CWP: $\chi^{2}=16.221, p=0.013$; Without CWP: $\chi^{2}=1584.129, p<0.0001$.

- Occupational categories: With CWP: $\chi^{2}=6.023, p=0.421$; Without CWP: $\chi^{2}=67.927, p<0.0001$.

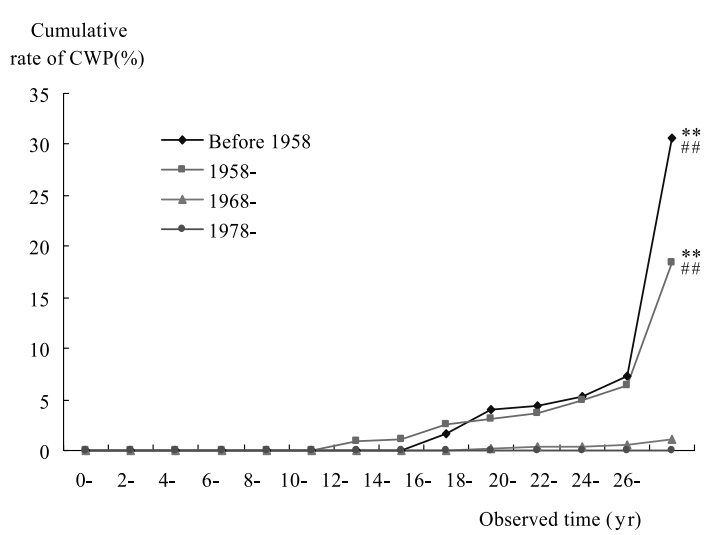

Fig. 1. Cumulative incidence rates of CWP among coal miners with different years of first dust exposure.

$* *$ indicate statistically significant difference $(p<0.01)$ as compared with the cohorts of 1968 - by Log-rank test, ${ }^{\# \#}$ compared with 1978-, $p<0.01$.

respectively. The distribution of incidence rates of CWP in four cohorts had statistically significant difference $\left(\chi^{2}=493.57, \quad p<0.0001\right)$. Cumulative rates of CWP declined dramatically among those coal miners beginning to be exposed to dust after 1968. Especially among those exposed to dust after 1978, the 30-yr cumulative incidence of CWP was only $0.06 \%$. Figure 2 shows that, the 55yr cumulative rate of CWP of tunneling miners was highest $(25.90 \%)$, but had not statistically significant difference as compared with the cumulative rate of CWP of combining miners $(14.53 \%)$. The 55 -yr cumulative rate of CWP of mining miners and that of helping miners were $7.26 \%$ and $0.89 \%$, respectively, and had shown sharp drop respectively, as compared with that of tunneling miners (Mining miners: $\chi^{2}=115.34, p<0.0001$; Helping miners: $\left.\chi^{2}=368.52, p<0.0001\right)$ and that of combining miners (Mining miners: $\chi^{2}=63.85, p<0.0001$; Helping miners: $\left.\chi^{2}=106.64, p<0.0001\right)$. No statistically significant differ-

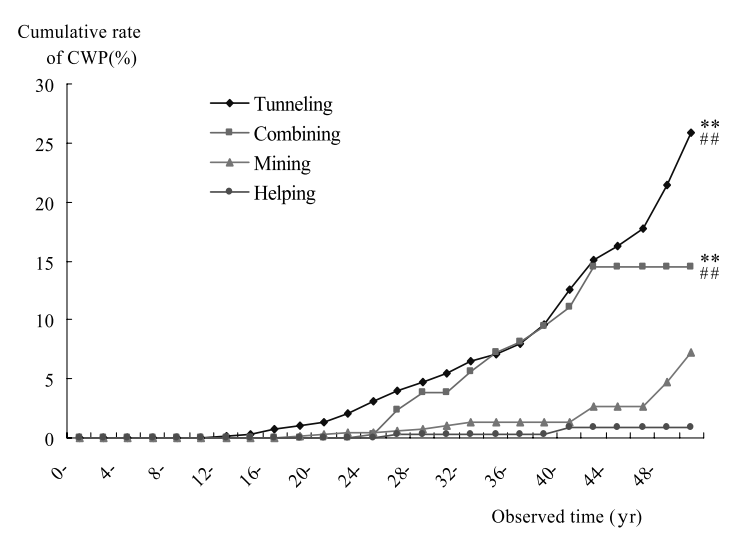

Fig. 2. Cumulative incidence rates of CWP among coal miners with different occupational categories.

**indicate statistically significant difference $(p<0.01)$ as compared with Mining by Log-rank test, ${ }^{\# \#}$ compared with Helping, $p<0.01$.

ence existed between the 55-yr cumulative incidence of CWP of mining miners and that of helping miners.

\section{Predicting new patients of CWP}

Table 3 shows that, of 15,390 healthy coal miners without CWP, 12,142 (78.89\%) began to experience dust exposure after 1978; 2,149 (13.96\%) began to be exposed to dust between 1968 and 1978. The number of new CWP patients predicted in future was approximate to 77. 41 (53.50\% of 77) were coal miners dust-exposed in 1958-1967. Among 5,454 healthy coal miners without CWP who worked in tunneling, about 66 (85.25\% of 77) could suffer from CWP in the future. By the end of 2007, there was not a coal miner with CWP among mining, combining and helping miners first dust-exposed after 1978, and so average incidence rates of CWP of those miners were zero. Therefore, only 11 new patients were predicted in 3,979 tunneling miners. It was predicted that 
Table 3. New patients with CWP predicted among healthy coal miners without CWP in different time periods

\begin{tabular}{|c|c|c|c|c|c|c|c|c|c|}
\hline \multirow{2}{*}{$\begin{array}{c}\text { Years of first } \\
\text { exposure }\end{array}$} & \multirow{2}{*}{$\begin{array}{c}\text { Occupational } \\
\text { categories }\end{array}$} & \multirow{2}{*}{$\begin{array}{l}\text { Healthy } \\
\text { coal miners }\end{array}$} & \multicolumn{7}{|c|}{ New patients predicted } \\
\hline & & & $2008-$ & $2013-$ & $2018-$ & $2023-$ & $2028-$ & $2033-$ & Total \\
\hline \multirow[t]{5}{*}{ Before 1958} & Tunneling & 102 & 2.85 & 2.39 & 0.88 & 0.02 & 0 & 0 & 6.14 \\
\hline & Mining & 111 & 1.21 & 1 & 0.29 & 0 & 0 & 0 & 2.5 \\
\hline & Combining & 1 & 0.01 & 0.01 & 0 & 0 & 0 & 0 & 0.02 \\
\hline & Helping & 42 & 0.07 & 0.04 & 0.02 & 0 & 0 & 0 & 0.13 \\
\hline & Total & 256 & 4.14 & 3.44 & 1.19 & 0.02 & 0 & 0 & 8.79 \\
\hline \multirow[t]{5}{*}{$1958-$} & Tunneling & 415 & 10.99 & 10.76 & 8.8 & 4.08 & 0.59 & 0 & 35.22 \\
\hline & Mining & 316 & 1.86 & 1.81 & 1.25 & 0.43 & 0.04 & 0 & 5.39 \\
\hline & Combining & 0 & 0 & 0 & 0 & 0 & 0 & 0 & 0 \\
\hline & Helping & 112 & 0.21 & 0.19 & 0.15 & 0.06 & 0.01 & 0 & 0.62 \\
\hline & Total & 843 & 13.06 & 12.76 & 10.2 & 4.57 & 0.64 & 0 & 41.23 \\
\hline \multirow[t]{5}{*}{$1968-$} & Tunneling & 958 & 2.74 & 2.74 & 2.72 & 2.64 & 2.3 & 0.69 & 13.83 \\
\hline & Mining & 509 & 0.29 & 0.29 & 0.28 & 0.28 & 0.25 & 0.06 & 1.45 \\
\hline & Combining & 117 & 0.1 & 0.1 & 0.01 & 0.1 & 0.09 & 0.14 & 0.54 \\
\hline & Helping & 565 & 0.14 & 0.14 & 0.14 & 0.13 & 0.12 & 0.05 & 0.72 \\
\hline & Total & 2,149 & 3.27 & 3.27 & 3.15 & 3.15 & 2.76 & 0.94 & 16.54 \\
\hline \multirow[t]{5}{*}{ 1978- } & Tunneling & 3,979 & 1.41 & 1.41 & 1.14 & 1.41 & 1.4 & 3.74 & 10.51 \\
\hline & Mining & 2,074 & 0 & 0 & 0 & 0 & 0 & 0 & 0 \\
\hline & Combining & 510 & 0 & 0 & 0 & 0 & 0 & 0 & 0 \\
\hline & Helping & 5,579 & 0 & 0 & 0 & 0 & 0 & 0 & 0 \\
\hline & Total & 12,142 & 1.41 & 1.41 & 1.14 & 1.41 & 1.4 & 3.74 & 10.51 \\
\hline Total & & 15,390 & 21.88 & 20.88 & 15.68 & 9.15 & 4.8 & 4.58 & 77.07 \\
\hline
\end{tabular}

about 72 and 5 coal miners could suffer from CWP in 2008-2033 and after 2033, respectively. For the next decade from 2008, the approximate number of new patients predicted was 43 , accounting for 55 percent of all patients with CWP predicted. In the period of the next $20 \mathrm{yr}$, there are about $68(87.70 \%)$ coal miners possibly suffering from CWP.

Table 4 shows that, about $9(11.81 \%)$ new patients with CWP are likely to be estimated to occur in 10,122 coal miners aged $45 \mathrm{yr}$ or younger, and $68(88.19 \%)$ could occur in the age group from 45 to 75 . In our study, there are 1,413 coal miners without CWP between the ages of 55 and 75 . Of those, 49 (63.97\% of 77) could be diagnosed as CWP within their life expectancies, and the average incidence rate of CWP in the future is $3.47 \%$, and ranges from $2.54 \%$ to $4.34 \%$ in different age groups.

\section{Discussion}

Although coal mine is known to be a high-risk area for the development of pneumoconiosis, CWP is entirely preventable through stringent and effective dust control ${ }^{16)}$. Some researches showed that the CWP prevalence declined markedly, highlighting feasibility and effectiveness of dust control in coal mines ${ }^{15,17,18)}$. It is consistent with results from observed a series of respiratory symptoms relating to the CWP and concurrent epidemio- logical investigations ${ }^{19}$.

In China, coal remains a major energy resource and about $50 \%$ of electricity is generated in coal-burning power plants. The estimated number of underground miners at present is about 6 million $^{20)}$. Although the prevalence of CWP should decrease dramatically in China ${ }^{21}$, the sheer number of 6 million coal miners still makes it a challenge to effectively prevent it and cure it or its complication.

This study evaluated the effects of the long-term work in the same colliery. The findings in this report indicate a continuing decline in CWP prevalence for coal miners with different exposure histories. The trend is similar to the previous results which were derived from some developed countries $\left.{ }^{9}, 22\right)$. The most likely reasons for the declines in prevalence are reductions in dust levels year after year owing to taking a variety of technical measures against dusts, 23). But, in the United State, severe cases of CWP continue to occur among coal miners in spite of significant progress made in reducing dust exposures in underground coal miners, and are mainly clustered in eastern Kentucky and western Virginia ${ }^{24)}$. It was a hint that there were inadequate prevention measures in specific regions.

This investigation also showed that the incidence of CWP among tunneling workers was by far higher than mining and helping workers. There were reports that workers from tunneling group had the highest dust expo- 
Table 4. New Patients of CWP predicted among healthy coal miners without CWP in different age groups

\begin{tabular}{|c|c|c|c|c|c|c|c|c|c|c|c|}
\hline \multirow{2}{*}{$\begin{array}{c}\text { Years of first } \\
\text { exposure }\end{array}$} & \multirow{2}{*}{$\begin{array}{c}\text { Occupational } \\
\text { categories }\end{array}$} & \multicolumn{10}{|c|}{ New patients predicted } \\
\hline & & $\begin{array}{l}<40 \\
(6,759) \wedge\end{array}$ & $\begin{array}{c}40- \\
(3,363)\end{array}$ & $\begin{array}{c}45- \\
(2,326)\end{array}$ & $\begin{array}{c}50- \\
(1,388)\end{array}$ & $\begin{array}{c}55- \\
(403)\end{array}$ & $\begin{array}{c}60- \\
(425)\end{array}$ & $\begin{array}{c}65- \\
(362)\end{array}$ & $\begin{array}{c}70- \\
(223)\end{array}$ & $\begin{array}{c}\geq 75 \\
(141)\end{array}$ & Total \\
\hline \multirow[t]{5}{*}{ Before 1958} & Tunneling & 0 & 0 & 0 & 0 & 0 & 0.1 & 2.71 & 1.95 & 1.38 & 6.14 \\
\hline & Mining & 0 & 0 & 0 & 0 & 0 & 0 & 0.84 & 1.08 & 0.58 & 2.5 \\
\hline & Combining & 0 & 0 & 0 & 0 & 0 & 0 & 0.02 & 0 & 0 & 0.02 \\
\hline & Helping & 0 & 0 & 0 & 0 & 0 & 0 & 0.03 & 0.04 & 0.06 & 0.13 \\
\hline & Total & 0 & 0 & 0 & 0 & 0 & 0.1 & 3.6 & 3.07 & 2.02 & 8.79 \\
\hline \multirow[t]{5}{*}{$1958-$} & Tunneling & 0 & 0 & 0 & 0.4 & 7.5 & 15.76 & 8.49 & 2.4 & 0.67 & 35.22 \\
\hline & Mining & 0 & 0 & 0 & 0 & 0.78 & 1.73 & 1.92 & 0.83 & 0.13 & 5.39 \\
\hline & Combining & 0 & 0 & 0 & 0 & 0 & 0 & 0 & 0 & 0 & 0 \\
\hline & Helping & 0 & 0 & 0 & 0 & 0.12 & 0.26 & 0.16 & 0.05 & 0.03 & 0.62 \\
\hline & Total & 0 & 0 & 0 & 0.4 & 8.4 & 17.75 & 10.57 & 3.28 & 0.83 & 41.23 \\
\hline \multirow[t]{5}{*}{$1968-$} & Tunneling & 0 & 0.04 & 3.73 & 7.88 & 1.58 & 0.53 & 0.05 & 0.02 & 0 & 13.83 \\
\hline & Mining & 0 & 0 & 0.34 & 0.9 & 0.15 & 0.04 & 0.01 & 0.01 & 0 & 1.45 \\
\hline & Combining & 0 & 0.01 & 0.31 & 0.2 & 0.01 & 0.01 & 0 & 0 & 0 & 0.54 \\
\hline & Helping & 0 & 0.01 & 0.35 & 0.28 & 0.06 & 0.02 & 0 & 0 & 0 & 0.72 \\
\hline & Total & 0 & 0.06 & 4.73 & 9.26 & 1.8 & 0.6 & 0.06 & 0.03 & 0 & 16.54 \\
\hline \multirow[t]{5}{*}{$1978-$} & Tunneling & 6.38 & 2.66 & 1.28 & 0.15 & 0.02 & 0.01 & 0.01 & 0 & 0 & 10.51 \\
\hline & Mining & 0 & 0 & 0 & 0 & 0 & 0 & 0 & 0 & 0 & 0 \\
\hline & Combining & 0 & 0 & 0 & 0 & 0 & 0 & 0 & 0 & 0 & 0 \\
\hline & Helping & 0 & 0 & 0 & 0 & 0 & 0 & 0 & 0 & 0 & 0 \\
\hline & Total & 6.38 & 2.66 & 1.28 & 0.15 & 0.02 & 0.01 & 0.01 & 0 & 0 & 10.51 \\
\hline Total & & 6.38 & 2.72 & 6.01 & 9.81 & 10.22 & 18.46 & 14.24 & 6.38 & 2.85 & 77.07 \\
\hline
\end{tabular}

- ( ) The number of healthy coal miners without CWP in different age groups in December, 2007.

sure $\left(10.3 \pm 16.3 \mathrm{mg} / \mathrm{m}^{3}\right.$ for current respiratory dust). Exposure results for mining and other workers were $0.66 \pm 0.61 \mathrm{mg} / \mathrm{m}^{3}$ and $0.88 \pm 1.6 \mathrm{mg} / \mathrm{m}^{3}$, respectively ${ }^{25)}$. Considering the cohorts, the number of patients with CWP also decreased from 1950s to 1970s. But CWP continued to occur among coal miners with first dust exposure before 1978, even among those having retired or switched to other dust-free job. The results highlight the importance of physical examination among coal miners ever exposed to dusty conditions for extended periods of time.

In China, there was a research to predict by the grey model of GM $(1,1)$ that there would be 28 new cases with CWP every year during 2001-2020 according to 2,296 miners with pneumoconiosis, and to indicate a downward trend of CWP in the future ${ }^{11)}$. Our study predicted new possible patients with CWP using the life-table method after stratifying for years to first dust exposure and occupational categories. The results are that, about 77 of 15,390 healthy coal miners without CWP are likely to develop CWP within their life expectancy. Of those, tunneling miners will be the major source of new CWP patients. 41 coal miners who had been exposed to dust during 1958 and 1968 could become CWP patients. Therefore, serious attention needs to be paid to those coal miners who worked on tunneling job between 1958 and 1978, especially in the last $20 \mathrm{yr}$ of their life expectancy (2008-2028). It was reported in British that, on the assumption that these miners start work at 18, after $20 \mathrm{yr}$, the rate of CWP (including PMF) would be $1.73 \%$ at age 38 . At the age of 48 and $58 \mathrm{yr}$ old, the incidence rates would be $4.54 \%$ and $8.85 \%$, respectively ${ }^{26)}$. Our study indicated that the average incidence rates of CWP were low in different age groups, and the highest rate was $4.34 \%$ in the group of 60-65 yr. The difference was likely to result from age at first exposure of those coal miners without CWP. In our study, most of coal miners started work at $22 \mathrm{yr}$ old.

Although the information reported in our study revealed a clear downward trend in CWP prevalence in the future, the development of new CWP patients would not be found in this colliery after $25 \mathrm{yr}$ or longer. In our retrospective study, life-table method, a simple yet effective approach, was used to make full use of the censored data, and obtain more valuable results ${ }^{27,28)}$. In addition, life-table method leads naturally to the log-rank test, which is more powerful than procedures based on comparing cumulative incidence rates at specified intervals. It also allows comparing differences after stratifying for important factors that may influence the incidence rates. Our analysis procedure about coal miners by life-table method was a simple and straightforward study, which could contribute 
immensely to evaluation of dust control efforts ${ }^{29}$.

In conclusion, the results presented herein demonstrate a reduction in CWP prevalence. But effective prevention measures are necessary to ensure that these gains are maintained, and hopefully advanced. Therefore it is especially important for surveillance of CWP to plan, implement, and evaluate those measures that are designed to prevent or control CWP.

\section{Acknowledgement}

This study was supported by a grant from Liaoning Provincial Natural Science Foundation (No. 20052219).

\section{References}

1) Scarisbrick DA, Quinlan RM (2005) Occupational respiratory disease in mining. Occup Med (Lond) 55, 72-3.

2) Attfield MD, Seixas NS (1995) Prevalence of pneumoconiosis and its relationship to dust exposure in a cohort of U.S. bituminous coal miners and ex-miners. Am J Ind Med 27, 137-51.

3) Scott DF, Grayson RL, Metz EA (2004) Disease and illness in U.S. mining, 1983-2001. J Occup Environ Med 46, 1272-7.

4) Marek K, Lebecki K (1999) Occurrence and prevention of coal miners' pneumoconiosis in Poland. Am J Ind Med 36, 610-7.

5) Goodwin S, Attfield MD (1998) Temporal trends in coal workers' pneumoconiosis prevalence: validating the national coal study results. J Occup Environ Med 40, 1065-71.

6) Shen HN, Jerng JS, Yu CJ, Yang PC (2004) Outcome of coal worker's pneumoconiosis with acute respiratory failure. Chest 125, 1052-8.

7) Naidoo RN, Robins TG, Murray J (2005) Respiratory outcomes among South African coal miners at autopsy. Am J Ind Med 48, 217-24.

8) Green FH, Althouse S, Weber KC (1989) Prevalence of silicosis at death in underground coal miners. Am J Ind Med 16, 605-15.

9) Attfield MD, Castellan RM (1992) Epidemiological data on US coal miners' pneumoconiosis 1960 to 1988. Am J Public Health 82, 964-70.

10) Melius JM, Sestito JP, Seligman PJ (1989) Occupational disease surveillance with existing data sources. Am J Public Health 79 (Suppl), 46-52.

11) Yang H, Yang L, Chu Q, Wang S, Lu D, Jia X, Li S, Song Z, Han G (2004) Analysis on pneumoconiosis characteristic and its prediction in one coal mine. J Hyg Res 33, 722-5 (in Chinese).

12) Parihar YS, Patnaik JP, Nema BK, Sahoo GB, Misra IB, Adhikary S (1997) Coal workers' pneumoconiosis: a study of prevalence in coal mines of eastern Madhya Pradesh and Orissa states of India. Ind Health 35, 467-73.

13) Huang $X, \mathrm{Li}$ WH, Attfield MD, Nádas A, Frenkel K,
Finkelman RB (2005) Mapping and prediction of coal workers' pneumoconiosis with bioavailable iron content in the bituminous coal. Environ Health Perspect 113, 964-8.

14) Mukherjee AK, Bhattacharya SK, Saiyed HZ (2005) Assessment of respirable dust and its free silica contents in different Indian coalmines. Ind Health 43, 277-84.

15) Attfield MD, Althouse RB (1992) Surveillance data on US coal miners' pneumoconiosis 1970 to 1986 . Am J Public Health 82, 971-7.

16) Kenny LC, Hurley F, Warren ND (2002) Estimation of the risk of contracting pneumoconiosis in the UK coal mining industry. Ann Occup Hyg 46 (Suppl 1), 257-60.

17) Heppleston AG (1988) Prevalence and pathogenesis of pneumoconiosis in coal workers. Environ Health Perspect 78, 159-70.

18) Wagner GR, Attfield MD, Kennedy RD, Parker JE (1992) The NIOSH B reader certification program - an updated report. J Occup Med 34, 879-84.

19) Soutar CA, Hurley JF, Miller BG, Cowie HA, Buchanan D (2004) Dust concentrations and respiratory risks in coalminers: key risk estimates from the British Pneumoconiosis Field Research. Occup Environ Med 61, 477-81.

20) Liu FD, Pan ZQ, Liu SL, Chen L, Ma JZ, Yang ML, Wang NP (2007) The estimation of the number of underground coal miners and the annual dose to coal miners in China. Health Phys 93, 127-32.

21) Liu B, Fan J, Shen S, Geng F, Liu T, Liu Z (2001) Study on the distribution pneumoconiosis and its dynamic trends among coal miners. Chin J Ind Hyg Occup Dis 19, 17-9 (in Chinese).

22) Smith DR, Leggat PA (2006) 24 years of pneumoconiosis mortality surveillance in Australia. J Occup Health 48, 309-13.

23) Weeks JL, ScD, CIH (2003) The fox guarding the chicken coop: monitoring exposure to respirable coal mine dust, 1969-2000. Am J Public Health 93, 1236-44.

24) Antao VC, Petsonk EL, Sokolow LZ, Wolfe AL, Pinheiro GA, Hale JM, Attfield MD (2005) Rapidly progressive coal workers' pneumoconiosis in the United States: geographic clustering and other factors. Occup Environ Med 62, 670-4.

25) Mamuya SH, Bråtveit M, Mashalla Y, Moen BE (2007) High prevalence of respiratory symptoms among workers in the development section of a manually operated coal mine in a developing country: a cross sectional study. BMC Public Health 7, 17-24.

26) Attfield MD (1992) British data on coal miners' pneumoconiosis and relevance to US conditions. Am J Public Health 82, 978-83.

27) Lou J, Zhou C (1989) The prevention of silicosis and prediction of its future prevalence in China. Am J Public Health 79, 1613-6.

28) Lee ET, Go OT (1997) Survival analysis in public health research. Annu Rev Public Health 18, 105-34.

29) David H, Myron E (1989) Lessons from silicosis control in China. Am J Public Health 79, 1599-600. 